\title{
Research on intellectual property strategy to promote the development of tourism branding in China
}

\author{
Lian Zhong ${ }^{1, *}$, and Yang Wang ${ }^{2}$ \\ ${ }^{1}$ Sichuan University, Law School, Chengdu, China \\ ${ }^{2}$ Sichuan University, Law School, Chengdu, China
}

\begin{abstract}
From the perspective of innovation, the current issue of China's tourism development is the insufficient development of tourism branding, which leads to the homogeneity phenomenon of tourism goods and services. As the intellectual property system stimulates creativity and protects innovation, this article suggests that the above-mentioned problem can be solved by effective intellectual property strategy, namely creating distinctive identities through trademark protection and use, and raising qualities of tourism brands through protection and use of geographical indication (GI). Specifically, the article firstly proposes the IP Strategy of creating distinctive identities of tourism brands by active registration, timely opposition and invalidity, and effective protection of trademarks. Secondly, it proposes the IP Strategy of raising qualities of tourism brands by active registration, effective protection and sufficient use of GIs.
\end{abstract}

\section{Introduction}

Tourism is one of the pillar industries of China's national economy. With China's economic development entering into the phase of "new normal", the strategy of innovation-driven development in the field of tourism has become a major theme of the times. The "13th Five-Year Tourism Development Plan (135 Plan 2016)" clearly states that, the transformation and upgrading of the tourism industry should be promoted by innovation. From the perspective of innovation, the current issue of China's tourism development is the insufficient development of tourism branding, which leads to the homogeneity phenomenon of tourism goods and services, such as imitating tourism park, mutual cloning of travel projects, and the lack of characteristics and creativity of tourism goods. ${ }^{[1]}$

The intellectual property system stimulates creativity and protects innovation, so the problem of the insufficient development of tourism branding can be solved by the intellectual property strategy. Tourism bands refer to the name, mark, symbol, of goods or services, as well as the combination of the above elements. They are used by tour operatives to indicate the source of tourism goods or services to consumers, and to endow the tourism goods or services with good brand reputation. Therefore, this paper aims to explore effective intellectual property strategies to promote the development of tourism branding in way of creating a distinctive identity and raising qualities of tourism brands.

\section{Distinctive Identities of tourism brands}

As creating a distinctive presence in the market is of interest to individual businesses and regions, the tourism brand plays an important role in protecting their competitive advantages for tour operators. As shown in the following figure 1, a joint survey showed that $98 \%$ of 1089 respondents considered tourism $\log$ to be "important" or "very important" for tourism destination promotion. ${ }^{[2]}$

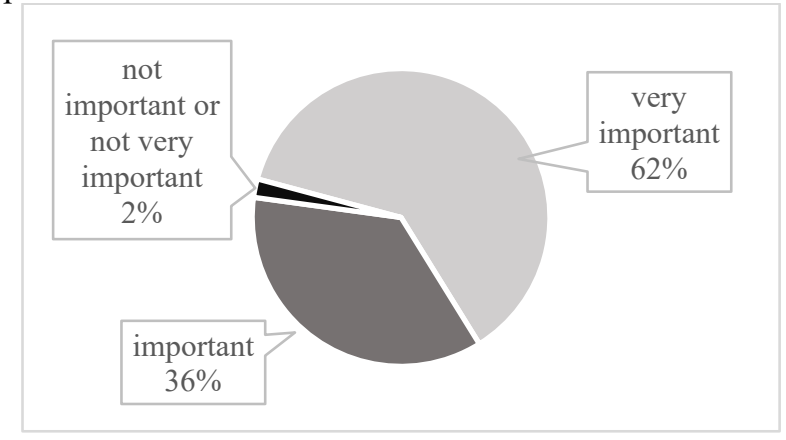

Fig 1. The result of the survey conducted by China Tourism News and the Media Research Lab at Tsinghua University

That is to say, a trademark, which is used to identify and distinguish the source of a party's goods or services, could create a distinctive appeal that will resonate amongst visitors. Therefore, the construction of tourism brand is relying on the effective protection and full use of trademarks. 


\subsection{Current status of the trademark protection and use of tourism in China}

\subsubsection{Current status}

For a long time, the identities of many tourism brands are not distinctive enough, for the protection and the use of the relevant trademarks are insufficient. The so-called "rush registration" to trademarks and the trademark counterfeiting still currently exist.

The "rush registration" refers to the act of applying for registration of an unregistered trademark that is already in use by others, or another's registered trademark in the category of goods or services that the registered trademark has not been approved for use. Many names of natural landscapes such as "Baotu Quan" and "Dongting Hu" and the names of the cultural sites such as "Sanxingdui" and "Jinggang Shan" have already been registered as trademarks. ${ }^{[3]}$

The trademark counterfeiting refers to the act of using a mark, which is identical or similar to a registered trademark in connection with the same or similar goods or services without the authorization of the owner of the registered trademark. For example, one kind of fried dough twist called "Chen Mahua" is a famous snack from the Chen Mahua Company in Ciqikou of Chongqing. As early as March 8, 2007, Chen Mahua company applied for the registration of "Chen Mahua" trademark on category 30 commodities (rice candy, crisp sugar, etc.), and this trademark was approved for registration in February 2012. However, nowadays when the visitors travel in Ciqikou and choose some fried dough twist with so-called trademark "Chen Mahua" as travel souvenir, most of the food are counterfeit goods, because they are not produced by the Chen Mahua Company.

\subsubsection{Reasons}

For the above problems, there are two main reasons as follows:

Firstly, there is not enough attention paid to the value of distinctive identities of tourism brand. Many tourism operatives fail to recognize the important value of trademark protection and use and some even are not aware of the serious consequences of trademark rush registration and counterfeiting. ${ }^{[4]}$ Even though the "135 Plan 2016" emphasizes the importance of nurture tourism brands, it does not address the appropriate way to protect and use the trademark in detail. In addition, the Tourist Attractions Branch of the China Tourism Association already issued the "Notice on Strengthening the Trademark Protection of scenic spot" in 2008, which points out the serious problem of rush registration of trademarks and suggests the way to protect tourism brands through trademark registration. However, it still fails to awaken the awareness of trademark protection and use among tourism operatives due to the shortage of detailed regulations.

Secondly, the relevant old legal system developed not well and created fertile ground for misbehaviour such as rush registration of trademarks and so on. For example, according to the Trademark Law of old version, only the pre-emptively registration of a trademark through unfair means that has been used by others and has acquired some reputation was not allowed, while the rush registration of the trademark without some reputation that has been used by others was not forbidden (Article 32). Particularly, the compensation for damages of trademark infringement under the old Trademark Law was imperfect, for the amount of compensation was believed to be low and the infringer was not properly punished. Therefore, the old legal system hindered the development of tourism branding in China.

\subsection{The strategy for creating distinctive identities of tourism brands}

China's Trademark Law is revised for the fourth time in 2019. This amendment aims to curb the trademark abusive registration and the trademark hoarding. Therefore, in view of the new revised Trademark Law, this paper proposes the following specific strategies for creating distinctive identities of tourism brands:

\subsubsection{Active Registration of trademarks based on actual use}

Trademarks can help to promote the development of the brand. The effective way to protect a brand is applying for the trademark registration and acquiring trademark exclusive right protection. ${ }^{[5]}$ Therefore, tourism operatives should firstly take stock of their core trademarks, and apply for the registration in time. These moves can make the operatives competitive. Secondly, besides core trademarks, the defensive trademarks and joint trademarks could also be considered to be registered. These trademarks can not only prevent others from registering the same or similar trademarks. They can also be regarded as reserve resources for tourism enterprises when they develop and expand. It is worth noting that, due to the maintenance cost of the trademark, the trademark registration should be carried out reasonably according to the actual demands.

\subsubsection{Timely Opposition and invalidity of trademarks against rush registration}

In order to curb the abusive registration and trademark hoarding, Article 4 of Trademark Law is revised and "applications for trademark registrations in bad faith which are not intended for use" is forbidden according to the revised Article 4. In addition, the regulations about the refusal of bad faith applications lacking any intention of use also have been executed in the opposition procedure (Article 33) and invalidity procedure (Article 44).

Since the new Trademark Law has come into effect, the above regulations are in favour of tourism operatives. Generally speaking, if the applicant had filed some trademarks, but with little information about the relevant tourism brands in public, then the trademarks may not be genuinely used. The regulations may help the tourism operatives against the rush registration of others in the opposition and invalidity procedure. 


\subsubsection{Effective protection of trademarks against infringement}

To prevent the counterfeiting of trademarks, tourism operatives should be aware of taking effective actions to protect their trademark rights in multiple ways. Firstly, where any party has committed any acts to infringe the exclusive right of a trademark, the tourism operatives can resolve the dispute through consultation. For example, for trademark infringements on e-commerce platforms, they could timely require the platform to remove the infringing goods through the complaints system of the platform. Secondly, if they are reluctant to resolve the matter through consultation or the consultation fails, they can also request the administrative authority for actions. Last but not the least, legal proceedings in the People's Court is a very important and effective way to help tourism operatives protecting their rights. Especially the new terms about compensation were imposed in the new Trademark Law, which increase the punishment of infringers and strengthen the protection to the trademark owners. For example, the trademark infringement committed in bad faith and with the serious circumstance, the amount of damage is raised to "more than one time but less than five times" of the amount assessed by referring to the calculation. The upper limit of legal damages is also raised to five million.

\section{Guaranteed Quality of tourism brands}

As the "135 Plan 2016" points out that one of the trends in China's tourism industry is the "quality of demand", the key element of tourism branding is the quality bound to origin. Different from trademarks, which identify a good or service as originating from a particular company, geographical indications (GIs) identify a good as originating from a particular place (Article 22, TRIPs). What's more, GIs denote that the products emanated from a certain geographical region and adhered to certain quality. Products that have gained quality assurance through the register of GIs have given rise to a fastgrowing tourism industry. Therefore, to strengthen the tourism branding based on the quality, the effective protection and full use of GIs should be sufficiently exploited.

\subsection{Current status of GI protection and use of tourism in China}

\subsubsection{Current status}

The protection and the use of tourism GIs remain underdeveloped in China and the tourism goods and services are very often standard and homogeneous, and lack of unique characteristics.

According to a statistical survey, most of the tourism goods are sold to retailers by wholesalers from the Yiwu market in Zhejiang. The goods from there are of single varieties, poor quality and similar appearance. ${ }^{[6]}$ Besides, some tourism goods with unique features are vulnerable to the fake goods. For example, an ordinary piece of embroidery, with different labels in different scenic spots, can be sold as "Su Embroidery", "Shu Embroidery" or "Gan Embroidery". The counterfeit affects the positive effect of authentic products among consumers and hinders the improvement of the quality of tourist goods.

Similarly, with regard to the quality of tourism service, getting rid of similarity and generalization and enhancing the regional characteristics remain major outstanding challenges.

\subsubsection{Reasons}

For the above problems, there are two main reasons as follows:

Firstly, there is not enough attention paid to the value of the GI protection and use for strengthening the tourism branding based on the quality. The drafters of the existing policies and documents related to tourism branding only mention the trademarks other than GIs for the construction of tourism branding. Even some discussions on the GIs related to the tourism branding only refers to the protection of GIs of scenic spots. ${ }^{[7]}$ Thus the awareness of the protection and use of GIs among tourism operatives are therefore not awaken yet. It is worth noting that the trademark itself is not directly linked to the quality of goods or services and a trademark register can only create distinctive identities rather than qualities of tourism goods or services. Qualified tourism goods or services should be in harmony with the local environment, which conforms to the requirements of GI products, because GI products adhere to stricter pre-defined criteria. GIs can endorse the quality of products.

Secondly, the Chinese old parallel-track legal protection system of GIs had a negative effect on the protection and use of GIs in tourism industry. As shown in the following figure 2, a GI might be registered either as a collective/certification mark according to the Chinese Trademark, or as a special mark, namely a "GI of origin" according to the "Regulations on the Protection of GIs". And the organisations to monitor the protection and use of the various indications were the State Administration for Industry and Commerce (SAIC) and the State Administration of quality supervision, inspection and quarantine (AQSIQ), respectively.

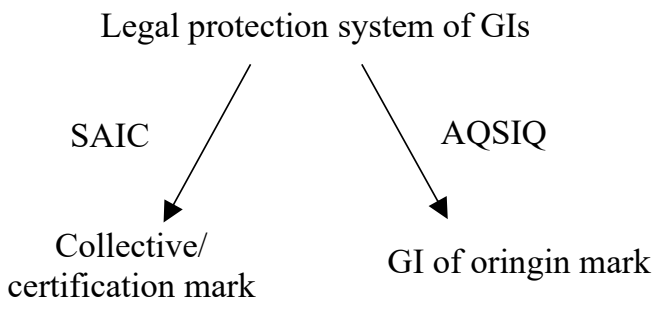

Fig 2. The parallel-track protection system of GIs.

Under this parallel-track protection system, the GIs were registered as various forms through different criteria. The registered indications were protected by different rules and the organisations to monitor the protection and use of the registered indications were different to ${ }^{[8]}$. Indeed, some rules appeared to be in conflict with each 
other and the organizational management and supervision system was also complex and overlapping. The application and administrative process became cumbersome and complicated, which raised the application costs and the difficulties of defending the corresponding rights for tourism operatives.

\subsection{The strategy for raising qualities of tourism brands}

In 2018, the institutional reform plan of China's State Council was adopted. The newly established State Intellectual Property Office (SIPO) integrated the responsibilities of trademark management of the SAIC and the responsibilities of GIs of origin management of the AQSIQ. The SIPO formulated the "Measures for the Administration of the Use of Special Indications for GIs (Trial)" in April and the "Regulations on the Protection of GI Products (Draft for Public Comments)" in September of 2020. These official actions showed the trends of the unified process of GI legislation and law enforcement. Therefore, in light of the above trends in the field of GIs, this paper makes the following specific recommendations for raising qualities of tourism brands:

\subsubsection{Active Registration of $\mathrm{G} / \mathrm{s}$}

Registered GIs are protected by laws and regulations against counterfeiting and other acts of abuses of GIs, which is beneficial for the quality promoting of tourism branding. However, the amount of registration of tourism related GI products is relatively small. By the end of October 2020, the number of GI products in China had reached 2,385 , but there were only around 50 GI products directly related to tourism, including the well-known tourism products such as Shu embroidery and Daoming bamboo weaving. Therefore, the local government and the tourism administration need to stress the importance of GIs and encourage the tourism operatives to make the GI applications. It should be noted that, the institutional reform makes the application procedure simpler and there are some steps vary. Relevant government departments should thus draft corresponding documents and conduct corresponding training to help the tourism operatives to get the new information.

\subsubsection{Effective Protection of G/s against Infringement}

GIs endow the products with good brand reputation and provide an avenue to the owner of the right to obtain additional revenue. These functions can be affected by the infringement of GIs. The infringement includes the act of using and making the names and special signs of GIs without authorization of the right holders, the act of using the names of GIs without meeting the pre-defined criteria of GI products and the management specifications for GI products, and the act of using a sign, which is identical or similar with a registered GIs without the authorization of right owners (Art.21 Regulations on the Protection of GIs). Against the above-mentioned infringements, the right owner and user of GIs should take action according to the relevant laws and regulations to protect their rights. The Bureau of Market Supervision and other relevant departments should also establish a dynamic management mechanism for the use of special marks for GIs to boost the development of tourism branding.

\subsubsection{Sufficient use of G/s}

Registered GIs can endorse the quality of tourism goods. More importantly, they can not only be a stand-alone tourism brand, but also may reside within an umbrella tourism brand applicable to a whole region. ${ }^{[9]}$ Therefore, regional tourism around products of GIs is a fast-growing segment of the tourism industry. GIs as bedrock among different tourism models such as "GIs + museums", "GIs + intangible heritage techniques" and "GIs + farming culture", should be sufficiently used by tourism operatives to establish high-quality tourism brands. ${ }^{[10]}$

\section{Conclusion}

The intellectual property system encourages creativity and protects innovation. The different elements in the tourism sectors may be well suited for branding through the use of trademarks and GIs, since trademarks create distinctive identities and GIs raise qualities of tourism brands. Therefore, as has been demonstrated, the intellectual property system provides very powerful tools for protecting competitive advantage and additional revenue streams to resolve the phenomenon of homogenization in the tourism industry and promote the development of tourism branding.

\section{Acknowledgment}

This article is the periodical achievement of "The 2019 Soft Science Research Project of State Intellectual Property Office (SS19-A-10)".

\section{References}

1. S.Z. Guo, M.C. Wu, Y.J. Lu, J KUNMING U SCI TECHNOL: SOC SCI, 5, 23-30 (2019)

2. W.J. Xu, CTNEWS, (2010-10-15)

3. Y.J. Zhang, J.X. Wang, J HEBEI INST SM, 2, 6264(2010)

4. B.X. Ma, S SCI TECHNOL ECO MARK, 12, 5455(2011)

5. J.H. Xu, C.Y. Xu, CHINA TM, 5, 16-22(2020)

6. P.F. Wang, J.M. Zhang, Z. Su, J MUDANJIANG U, 7, 76-79(2009)

7. L. Zhong, J HUAZHONG SCI TECHNOL: SOC SCI, 1, 84-92(2020)

8. Q.F. Zhu, Y.F. Wang, C.C. Wang, J.J. Lu, M.Y. Wu, Chinese Society for Environmental Sciences, 1(2019)

9. T. Nanayakkara, Role of Intellectual Property in Enhancing the Competitiveness of the Tourism 
Industry.

https://www.wipo.int/export/sites/www/sme/en/touri sm/tourism_ip.pdf 